\title{
Human Resource Management from a Justice-Based Perspective
}

\author{
Tahir Masood Qureshi ${ }^{1}$, Mohemmed Absuweilem ${ }^{1}$, Shareefa Reda Alkhateeb ${ }^{1}$, \\ Verl Anderson ${ }^{2} \&$ Cam Caldwell $^{1}$ \\ ${ }^{1}$ American University in the Emirates, United Arab Emirates \\ ${ }^{2}$ Dixie State University, United States \\ Correspondence: Dr. Verl Anderson, Dixie State University, United States.
}

Received: October 21, 2020

doi:10.5430/bmr.v9n4p9
Accepted: November 15, 2020 Online Published: December 4, 2020

URL: https://doi.org/10.5430/bmr.v9n4p9

\begin{abstract}
It is axiomatic to acknowledge that the Human Resource Management (HRM) function plays a vital ethically-based role in honoring duties owed to organization employees and other stakeholders. Incorporating the research of the University of Michigan ethics expert, LaRue Hosmer, this paper identifies nine qualities associated with organizational justice as they relate to seven important HRM responsibilities. This paper then offers five guidelines for Human Resource Professionals to consider in honoring their justice-related obligations to those whom they serve.
\end{abstract}

Keywords: Human Resource Management Responsibilities, Organizational justice and Human Resources, Hosmer Decision-making Model, Organizational Trustworthiness

\section{Introduction}

Nearly twenty-five years ago, the University of Michigan's LaRue Hosmer (1987), wrote a compelling article in which he opined that virtually every Human Resource Management (HRM) activity, program, or practice was fraught with ethical implications. Hosmer explained that any action which materially affected the interests and rights of employees involved a complex set of ethical duties. Hosmer later developed a model for ethical decision-making that identified the process for leaders and managers to justify and explain the decisions that they make.

The purpose of this paper is to address the justice-related impacts of seven important HRM responsibilities and to affirm the wisdom of Hosmer's decision-making model as it applies to making just HRM decisions. The paper begins by offering a definition of justice as an organizational obligation-citing nine different qualities associated with justice from the scholarly literature. After linking the close relationship between justice and perceived trustworthiness, we then present the Hosmer model of ethical decision-making as a standard for evaluating just decisions. Using the definitions of justice and the Hosmer model, we identify how seven important HRM responsibilities impact individuals/stakeholders who either are applicants for positions, new employees, or current employees in today's organizations-including the Top Management Team (TMT), the managers, and supervisors who are affected by HRM decisions.

Following this review of justice-related responsibilities of Human Resource Professionals (HRPs), we offer five guidelines which HRPs should carefully consider as they reflect on their justice-related obligations and the duties that they owe to stakeholders. We then suggest four contributions made by this paper to both organizational practitioners and scholars who study HRM responsibilities. The paper concludes with a challenge to practitioners and academics to thoughtfully evaluate the implications of the insights provided herein.

\section{Justice as an Organizational Obligation}

Justice in organizations refers to the degree that organizations demonstrate distributive, procedural, and interactional fairness to stakeholders (Colquitt et al., 2005). Those three different but related types of justice are the means by which organizational leaders demonstrate that they are both fair and trustworthy in establishing relationships with their stakeholders (Colquitt \& Rodell, 2011). Understanding the subjective nature of justice and its influence on how leaders are perceived has clarified the complexity of the construct and emphasizes its multidimensional qualities.

According to the justice literature, the nature of justice includes nine different facets. The following is a brief synopsis of each of the dimensions of justice: 
a). Distributive Justice is based upon the values that determine the socially just allocation of resources, often referring to the degree that these values determine the nature of that distribution (Rawls, 1999). In determining that allocation three primary methods are used (Primeaux et al., 2003).

b). Equality-based Distribution - Allocating resources based upon equality shares the distribution equally among the parties, with each individual receiving the same share. The assumption behind this approach is that all participants should benefit equally.

c). Equity-based Distribution - The equity-based allocation of resources assigns a distribution based upon the relative contribution of individuals to the achievement of goals. The underlying assumptions that determine this distribution are that those who contribute the most should receive a greater allocation and that the relative contribution can be reasonably determined.

d). Need-based Distribution - A need-based distribution allocates resources according to the relative needs of the individuals who are part of an organization. The assumption of this distribution is that those with greater needs ought to receive a share according to the needs that they have.

e). Procedural Justice addresses the transparency and rational reasonableness of the processes used in resolving disputes or allocating resources. Three frequently-cited characteristics of procedural justice are also identified.

f). Objective Process Rationality - The inherent logic and rationality of the governing rules for determining decisions demonstrates their objective fairness for all parties. The assumption is that the values that determine outcomes are consistent with universal principles and the public interest.

g). Opportunity to be Heard - The opportunity to be able to present one's position and to advocate for the resolution of a problem is deemed essential for justice to result. The assumption is that this opportunity to explain one's perspective enables the affected party to justify the reasonableness of his/her position.

h). Adherence to Established Rules - The degree to which due process follows the established procedures and rules which are adopted ensure that individual rights are protected. The assumption is that knowing the ground rules and feeling confident that they have been consistently applied enables all parties to believe that their personal rights are considered.

i). Interactional Justice addresses the requirement that all parties are dealt with in a respectful and dignified matter and with a concern for their best interests. Three elements of interactional justice make up this category as well.

j). Treatment with Courtesy and Respect - All parties are treated in a polite, courteous, and respectful manner and with an acknowledgement of their individual value. The assumption is that the courteous treatment of all parties reflects the objective process by which people's interests are determined.

k). Commitment to Individual Welfare - The best interests of individuals are acknowledged and the determination of outcomes is based upon that which benefits the participants to the degree possible. The assumption is that individual rights are respected and that the outcomes sought include the optimization of benefits for all parties involved.

1). Explanation of Decisions - The determination of the outcomes of a decision are to be clearly explained, including the rationale used in weighing the costs and benefits and the impacts on individual rights - as well as the ethical, legal, and economic criteria upon which the decision was made. The assumption is that this explanation acknowledges the parties' right to understand the basis for decisions.

Each of these nine facets of justice have been widely-acknowledged for having an important impact on how leaders of organizations lead and how Human Resource Professionals interact with others (Foger \& Cropanzono, 1998).

\section{Justice and Trustworthiness}

The correlation between perceptions about justice and trustworthiness is well documented. Beliefs that individuals are treated justly result in expanded organizational citizenship behaviors, task performance, and personal commitment (Cohen-Carash \& Spector, 2001). Justice is equated with the truthfulness of an individual or organization and the violation of the standard of truthfulness is inherently in conflict with moral norms (Colquitt, 2001). Both justice and trustworthiness are advocated as antecedents to trust (Colquitt \& Rodell, 2011).

Empirical evidence also suggests that trustworthiness and justice are closely related. Clapham and colleagues (Clapham et al., 2014) found that both trustworthiness and justice were constructs that are individually perceived through the mediating lens, or the subjective perceptions, of each individual. The factors of ability, benevolence, and integrity that are the universally acknowledged foundations of trustworthiness (Mayer et al., 1995) have each been found to be statistically correlated with the elements of both procedural and interactional justice (Clapham, 2014). 
The practical logic of interpersonal relationships also confirms that people expect that those with whom they work will be fair - and that their leaders will have their interests at heart. The nature of both justice and trustworthiness is that they both contain obligations requiring that those who lead are honorable and tell the truth, competent in performing tasks, and respectful and committed in the relationships that they establish (Colquitt, 2011).

For HRPs, their ability to perform their jobs also depends upon their perceived integrity, their commitment to their employees' best interests, and their professional competence (Caldwell \& Anderson, 2018). Each of these factors encompasses the key elements of both trustworthiness and justice in interpersonal and organizational relationships and influences whether the relationship between two parties is arms-length or collaborative (Caldwell \& Anderson, 2019). A growing body of statistical evidence confirms that the integration of an organizational culture based upon high trust with aligned HRM practices not only enhances employee commitment but increases productivity, profitability, and customer satisfaction (Beer, 2009).

\section{Justice and the Hosmer Model}

LaRue Hosmer (Hosmer, 2010) developed a comprehensive model for ethical decision-making that closely parallels the justice-related responsibilities of leaders and enables them to honor the obligations of procedural and interactional fairness owed to others. This model, shown below as Figure 1, consists of eleven factors.

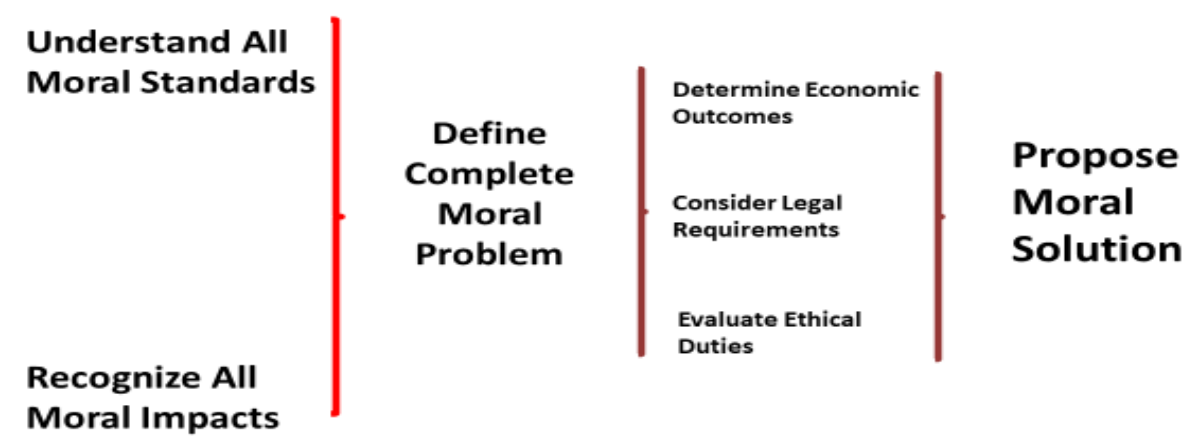

Figure 1. The Hosmer Decision-Making Model

The following is a brief synopsis of each of the factors in the Hosmer Model that contribute to understanding justice:

a). Understand All Moral Standards - Implicit in the model is the responsibility of a leader to consider and enumerate the moral standards by which (s)he makes decisions that affect stakeholders. Because ethical standards vary from person to person, the leader has the obligation to explain the moral criterial by which decisions are framed.

b). Recognize All Moral Impacts - The consequences of decisions affect multiple stakeholders and the relationship between a leader and those stakeholders requires that the leader accept and honor the moral consequence of his or her decisions.

c). Benefits to Some - A leader's actions are purposive and are intended to add value. The creation of added value is a primary factor in justifying the actions undertaken and their consequences. Actions that do not add net value are inconsistent with moral and ethical criteria.

d). Harm to Others - A leader is also obligated to acknowledge that actions taken may actually have a harmful impact on others. Recognizing and addressing these consequences enables a leader to demonstrate her/his awareness of the decision made and places the harm in context with benefits.

f). Rights Honored - Basic rights of stakeholders influence the leader's moral responsibility, particularly when there is a special relation owed by the leader and her/his organization that imposes a duty of due care associated with the honored rights. 
g). Rights Denied - When a decision denies the rights of one or more stakeholders, the leader is obligated to acknowledge those consequences and to justify them in terms of an overall net benefit. A leader may also have an obligation to address how the rights denied may be addressed by subsequent decisions.

h). Define Complete Moral Problem - After examining the costs, benefits, and consequences of alternative options, a leader has the obligation to clearly frame the moral problem that (s)he has ultimately concluded is her/his responsibility. Defining this problem incorporates the purposes of the leader's actions and the goals to be achieved thereby.

i). Determine Economic Outcomes - The financial and economic outcomes that accompany the alternative choices to be made need to be estimated to the greatest extent possible. Those outcomes include both present and future costs, resources required, and opportunity costs associated with the alternatives considered.

j). Consider Legal Requirements - The decisions considered may or may not have significant legal consequences, including the possibility of legal actions taken by injured parties from the respective decisions. The probability of legal actions taken as a result of the respective alternatives must be taken into consideration.

k). Evaluate Ethical Duties - The broad range of ethical duties and their sometimes-conflicting priorities accompany every leader's actions. By acknowledging the ethical standards considered and the implications of choices made and not made, a leader is able to clarify the ethical rationale for a decision selected.

1). Propose Moral Solution - The leader explains the moral choice made and the factors that he considered throughout the decision-making process. This explanation demonstrates not only the leader's rationale but her/his respect for the impacts of the preferred decision on stakeholders and their right to understand why choices were made or not made.

Each of these eleven factors of the Hosmer model reflects the leader's awareness of the moral and ethical consequences of her/his responsibilities and the process that the leader has used to carefully evaluate alternatives-ultimately resulting in the leader's decision.

Implicit in the Hosmer model is its fundamental logic, its incorporation of the distributive impact of choices, its sensitivity to a rational and logical process and outcome, and the need to demonstrate respect for the affected stakeholders and their right to understand the rationale for decisions. Each of these factors are consistent with the standards of distributive, procedural, and interactional justice and reflect a leader's recognition of the importance of decisions and their ethical implications. As applied to HRM, the Hosmer model is a powerful standard for evaluating the justice-related qualities of HRM's responsibilities to stakeholders.

\section{Seven HRM Responsibilities}

In its staff support role, HRM serves the Top Management Team (TMT) in assisting an organization to accomplish its strategic objectives and in that role HRPs best function as ethical stewards who fill quasi-sacred obligations (Caldwell \& Anderson, 2018). The competencies required to serve an organization are substantial, but are rarely fully understood and often not performed effectively (Gomez-Mejia et al., 2015). For that reason, HRM has struggled for decades to be considered a valued member of an organization's strategic team-despite the evidence that High Performance Work Systems that align HRM functions are a key to organizational profitability (Boxal \& Macky, 2009).

In this section we identify seven important HRM responsibilities and incorporate the nine different justice characteristics and the Hosmer model to demonstrate that each of these responsibilities contain important justice-related elements. By demonstrating the elements of justice that are present and clearly important in all seven of these responsibilities, we clarify the importance of HRPs understanding the subtle nature of the nine justice characteristics. As HRPs incorporate principles of justice in carrying out their duties, they honor their ethical obligations and establish relationships with employees and other stakeholders that exemplify the credibility of their organizations and its commitment to excellence.

\subsection{Selection and Testing}

Among the most sophisticated of HRM responsibilities, the selection and testing of job candidates - both for new entrants to the organization and for promotional opportunities - is particularly challenging but not always performed according to best standards of the HRM profession (Farr \& Tippins, 2013). The failure of many organizations to conduct a valid job analysis prior to filling job vacancies is a classic problem that often occurs (Morgeson et al., 2019). A poor job analysis is an organizational hindrance in identifying the best candidates for a position (Prien et al., 2009) and can seriously impair an organization's effectiveness (Collins, 2001). 
In addition to failing to honor their obligation to their organization by failing to develop an accurate assessment of job requirements, HRPs also fail to honor their responsibilities to job candidates - whether inside or outside the organization (Van Buren et al., 2011). From a procedural justice perspective, HRPs often fail to establish selection and testing processes that are logical and defensible. When selection and testing processes are not validated, job-related, and properly administered, the outcomes are both distributively unjust and subject to challenge legally (Gatewood et al., 2015).

Interactional justice violations on the part of many HRPs also occur when job candidates are not responded to, or are "ghosted," when HRPs fail to communicate to applicants about the results of a testing and selection process. HRPs rarely do more than send candidates the "form letter" response that "a better candidate was hired that better fit the needs of our organization" with no specific feedback about a candidate's qualifications or an explanation about the hiring process (Caldwell et al., 2003). Job candidates, particularly internal candidates for promotional positions, deserve greater respect and more specific feedback - even if HRPs are busy and feel that their workload is demanding.

\subsection{New Employee Onboarding}

The integration of new employees into an organization is not always done well, even for management level employees (Derven, 2008). Onboarding is the process by which individuals have their first introduction to an organization, its culture, the values that it emphasizes, and its commitment to employees' welfare (Hillman, 2010). Unfortunately, the implied obligation to help new employees to get the best possible start as individuals unfamiliar to an organization is often poorly done (Caldwell \& Peters, in press).

The process involved in onboarding is frequently rushed. Prior to beginning their work as new organization members, most newly hired individuals are hopeful that they will receive information that will enable them to hit the ground running and the most effective organizations recognize that onboarding is optimally successful when they lay the foundation for new hires to have a smooth transition. Unfortunately, many organizations overwhelm new employees with information that could easily be communicated to them with enough time for those individuals to prepare for their new assignments. Establishing mentors can be especially effective in onboarding, especially when those mentors reach out to new employees well before they actually begin their first day on the job (Baurer \& Erdogan, 2011).

Onboarding is procedurally fairest and most effective when employees and their mentors are able to have ongoing dialogue with enough time for the new employee to process what often seems to be an endless set of paperwork requirements and time deadlines that make it challenging to complete required onboarding tasks. Onboarding is often made difficult when new employees are inundated with orientation meetings, new procedures, and an unfamiliar software system (Caldwell \& Peters, in press).

The opportunity to be heard, a basic element of procedural justice, is sometimes overlooked when onboarding focuses on disseminating information without actually allowing employees enough time to digest what they are learning and ask questions about the subtle nuances that often are difficult to understand without one-on-one coaching. Interactionally, the best interests of new employees and the organization are achieved when the onboarding process recognizes that individuals may vary in their familiarity with the unique characteristics of their new company (Ellinger et al., 2011).

\subsection{Compensation and Benefits}

Compensation includes making sure that the right persons receive the correct pay for achieving the proper objectives in the right way (Milkovich et al., 2013). Alignment, or fairness related to compensation, requires a judicious understanding of the content of a position, the relative worth of that position in the external marketplace, and the internal equity of a company's compensation plan (Agbo, 2019).

In acquiring talent, an organization's compensation philosophy must also respect the fact that "rank in position; or the relative weighting of the tasks, job requirements, and comparative value assigned to a job, must also be adjusted based upon the "rank in person;" or the valuable, rare, difficult to imitate, and organizationally essential capabilities of a candidate who is able to add unique value to an organization (Moriarty, 2020).

In his 2019 Presidential Address to the Society for Business Ethics, Jeffrey Moriarty (2020) explained that compensation was 1): a reward given for the achievement of a valued task; 2): an incentive that is used to attract and retain workers and to inspire hard work; and 3) the indicator of the price of labor within a marketplace, reflecting the perceived value of the individual and the work to be performed. 
Although compensation and benefits reflect a primary focus on distributive justice, the procedures followed in determining relative compensation and the interactional relationship between the parties can also influence the degree of satisfaction or dissatisfaction of employees within an organization (Osibanjo et al., 2014). Thus, in compensating employees all three forms of justice must be understood by HRM personnel (Scarpello \& Carraher, 2008; Mckenna \& Beech, 2008).

\subsection{Training and Development}

Developing and training employees has become the cornerstone of the human resource strategies of the organization in order to ensure improvement of performance (McKenna \& Beech, 2008; Shrouf et al., 2020). Training and development programs can enable organizations to invest in their employees' skills and can benefit both the organization and the individual - when done well. Unfortunately, the empirical evidence suggests that such training is often poorly delivered and focused on metrics and methods that fail to benefit either the employee or the organization.

The deficiencies of many training and development programs are legendary in many organizations with managers and supervisors often failing to understand the concepts which employees are trained to incorporate on the job (Noe, 1993). Wise organizations and effective HRM professionals base training and development on a thoughtful needs assessment -- coupled with support systems that reinforce training concepts within the work environment. Such training includes courses both attended by and actually taught by supervisors and managers who then help employees to implement that training (Biech, 2018).

The opportunity for training in organizations is often viewed as a cost that negatively affects this quarter's profit picture - despite the fact that training and development programs, when well developed and focused on creating organization value - have been proven to create a positive return on investment for decades (Phillips, 2012). Consequently, both organizations and the employees who work within them fail to improve their productivity, undermine their long-term profitability, and ultimately lose their competitive position in a world where good is no longer good enough (Collins, 2001).

\subsection{Job Analysis and Design}

Job analysis is the building block of HRM and is critical to properly addressing many other elements of an organization's relationships with employees (Caldwell \& Anderson, 2018). When done properly, a job analysis provides valuable information that identifies the key tasks to be performed, the personal qualifications that match those tasks, and the critical competitive advantage factors that enable an organization to excel (Morgeson et al., 2019).

Consistent with principles of procedural justice, a well-crafted job analysis objectively identifies the tasks required of employees that determine their job responsibilities, their job description, their compensation rate, and their performance expectations (Hartley, 2004). Wise HRM staff provide employees with the opportunity to review the job analysis summarizing their positions and to actively be a part of the process of developing the final document.

Done well, the job analysis demonstrates to employees that the organization and their supervisor understand what is expected of each employee and recognize the organization's responsibility to assist each employee to succeed on the job. By demonstrating this professional courtesy, organization members and the HRM Department honor their interactional justice obligations to employees.

\subsection{Employee Assessment and Coaching}

The performance appraisal process has been widely condemned for decades as being inconsistent, arbitrary, and unjust (McGregor, 2016). Holding employees accountable for the errors that occur as a result of faulty organizational systems and processes has also been acknowledged to be inconsistent with the true systemic causes of poor performance (Deming. 2000).

HRM professionals have come to recognize that coaching employees and focusing on improving their performance -rather than pointing out their deficiencies - is a far more productive and more ethical practice that honors the organization's responsibilities to employees (Cooper et al., 2014). Leaders who seek to bring out the best in their employees not only help their employees to flourish but empower those same employees to contribute to their organization's success (Covey, 2004).

\subsection{Employee Relations}

The employee relations role of HRM professionals not only honors employees and treats them as valued partners but creates the high-trust culture that generates employee commitment, ownership, and creative innovation (Beer, 2009). 
High-Performance Work Systems incorporate an organization's commitment to employees' best interests and are based upon an organizational culture that engages and empowers employees (Boxal \& Macky, 2009).

Employee relations is sometimes equated with unions and employee contracts. In truth, organizations can establish positive relationships with employees in organizations of all types (Aylott, 2018). Formal union contracts ensure the procedural security of employees and protect them against arbitrary and capricious actions of employers.

In commenting on the quality of employee relations established in organizations, Stanford University's Jeffrey Pfeffer (1998) noted that organizations earn the type of relationships that they have with their employees by the ways that those employees are treated. When treated fairly and consistently, employees are far more likely to respond with hard work and a positive commitment to their organization and its mission (Clifton \& Harter, 2019).

\section{Five Guidelines for Human Resource Professionals}

As HRPs reflect on the importance of justice, fairness, and trustworthiness in the performance of their responsibilities, they are able to develop a greater appreciation of the importance of their strategic role in their organizations and their obligations as stewards of the organization (Caldwell et al., 2001). Consistent with that ethical stewardship set of responsibilities, we suggest five guidelines for HRPs to consider as they reflect on the tremendous importance of their organizational roles.

6.1 The Responsibilities of HRPs Encompass Their Personal Examples in Modeling the Standards of distributive, Procedural, and Interactional Justice.

As representatives of the TMT, HRPs have the absolute obligation to model the way in exemplifying their organization's values (Schein \& Schein, 2016) and in honoring the ethical obligations implicit in these three facets of organizational and interpersonal justice (Kouzes \& Posner, 2011).

6.2 HRPs are Most Effective Strategically When They Seek Long-Term Outcomes Focused on Optimizing Wealth Creation.

The stewardship responsibilities of transformative leadership that are part of each HRPs role demand that HRPs focus on long-term wealth creation (Caldwell, 2011). The seductive attraction of short-term options that actually undermine the future of an organization must not compromise the ability of an organization to benefit all of its stakeholders

6.3 HRPs Must Model the Values Implicit in Justice by Demonstrating Their Commitment to Employees' Welfare - as well as that of the Organization.

As stewards of a company's best interests, leaders acknowledge the importance of win-win choices that best serve the needs of employees AND the organization in the pursuit of value creation, improved customer service, and productivity (DePree, 2004; Burns, 2010). HRPs who demonstrate their commitment to employees' welfare, growth, and wholeness - as well as the success of the organization - honor an organization's highest standards and are perceived as credible and trustworthy (Kouzes \& Posner, 2011).

6.4 HRPs Must Constantly be Developing the Knowledge, Skills, and Abilities Necessary to Perform HRM Duties to Comply with Best Practices of Their Profession.

The complexities of the HRM role are many and sophisticated and require many years of skill development, study, and practical experience to fully master (Gomez-Mejia et al., 2015). The personal investment and dedication required to excel as an HRP demands a diligent commitment to personal excellence.

6.5 HRPs have a Moral and Ethical Obligation to Their TMTs to Communicate to Their Leaders the Ramifications of Policies, Procedures, and Practices that Conflict with the Many and Varied Qualities of Justice.

In their staff role in organizations, HRPs have an absolute obligation to their TMTs to alert them when policies, procedures and practices in the organization undermine the organization's values or serve to convey a message that is inconsistent with the principles of organizational justice and the highest standard of ethical stewardship (Mathis et al., 2016).

As HRPs incorporate these suggestions into their professional lives, they enhance the ability of their organizations to accomplish their intended purposes. Along the way, HRPs also become more valuable to their organizations as strategic partners and enhance their ability to build a culture of trust, respect, and excellence. 


\section{Contributions of the Paper}

In this presentation of information about the importance of the broad nature of justice as it applies to the HRM function, this paper makes four significant contributions to the academic literature and to HRP practitioners.

7.1 It Affirms the Importance of Distributive, Procedural, and Interactional Justice and the Hosmer Model as Standards for Performing Seven Important HRM Roles.

Each of those qualities of justice are important in honoring duties owed to employees and to organization (Cropanzono et al., 2007).

7.2 It Emphasizes the Profoundly Ethical Nature of HRP Responsibilities in Serving Stakeholders - Ranging from Job Applicants and Employees to an Organization'S TMT.

As HRPs model ethical values, they send a powerful message to employees about the integrity of the organization and its leadership and demonstrate the credibility of organization leaders (Schein \& Schein, 2016).

7.3 It Confirms the Importance of a Win-Win Approach in Pursuing the long-Term Best Interests of an Organization While Honoring Duties Owed by Organizations to Their Employees.

This win-win approach to organizational and interpersonal relationships increases the commitment to shared values and reciprocity that are vital to cooperation Covey, (2013).

7.4 It Helps to Explain the Level of Interpersonal, Organizational, and Professional Competence and Expertise Demanded of HRPs and the Need for HRPS to Constantly Enhance Their Knowledge and Skills.

In a world where HRPs are often poorly trained and inadequately prepared to perform the vital functions of their profession (Gomez-Majia et al., 2015), the need for constant learning and continuous improvement is essential for HRPs to be perceived as adequately prepared to perform their jobs.

As scholars and practitioners reflect on these four significant contributions and discuss their ramifications, they have the opportunity to increase the ability of the HRM profession to understand how it can increase its impact on organizations. In addition to creating healthier relationships and a more enriching organizational culture, the application of the principles of distributive, procedural, and interactional justice can enable organizations to model the values that can enable organizations to flourish.

\section{Conclusion}

Organizations today struggle to earn the commitment, support, and followership required to be successful. The recent research of the Gallup organization confirms that employees do not feel either engaged or empowered (Mathis et al., 2015) and a Harvard Business Review article reported that trust in leaders in virtually every type of organization is low (Clifton \& Harter, 2019).

As LaRue Hosmer (1995) noted twenty-five years ago, the actions of organizations in conducting HRM functions have profound ethical implications. Organizations that struggle to earn the followership and commitment of their employees lose the ability to compete effectively in today's extremely competitive global context (Harrington, 2017). As HRPs increase their understanding of the importance of justice and its implications in their organizations - and as they develop their knowledge and skills to demonstrate their trustworthiness - they have the opportunity to make a major contribution to their organizations' success.

\section{References}

Agbo, M. U. A. M. U. (2019) Effects of Compensation Plan on Employee Performance in the Telecommunication Industry (A study of MTN and GLO Nigerian Ltd Umuahia Branch).

Aylott, E. (2018). Employee Relations: A Practical Introduction. London, UK: Kogan Page.

Bauer, T. N., \& Erdogan, B. (2011). Organizational socialization: The effective onboarding of new employees. https://doi.org/10.1037/12171-002

Beer, M. (2009). High Commitment High Performance: How to Build a Resilient Organization for Sustained Advantage. San Francisco, CA: Jossey-Bass.

Biech, E. (2018). Skills for career success: maximizing your potential at work. New York: Berrett-Koehloer Publishers. 
Boxall, P., \& Macky, K. (2009). Research and theory on high-performance work systems: progressing the highinvolvement stream. Human resource management journal, 19(1), 3-23. https://doi.org/10.1111/j.1748-8583.2008.00082.x

Burns, J. M. (2010). Leadership. New York: Harper Perennial.

Caldwell, C., \& Anderson, V. (2018). Strategic Human Resource Management. Hauppage, NY: NOVA Publishing

Caldwell, C., \& Anderson, V. (2019). Leading with Love. Hauppage, NY: NOVA Publications.

Caldwell, C., \& Peters, R. (In Press). New Employee Onboarding - Psychological Contracts and Ethical Perspectives. Journal of Management Development.

Caldwell, C., Thornton, G. C. III., \& Gruys, M. (2003). Ten Classic Assessment Center Errors: Challenges to Selection Validity. Public Personnel Management, 32(1), 73-88. https://doi.org/10.1177/009102600303200104

Caldwell, C., Truong, D., Linh, P., \& Tuan, A. (2011). Strategic Human Resource Management as Ethical Stewardship. Journal of Business Ethics, 98(1), 171-182. https://doi.org/10.1007/s10551-010-0541-y

Clapham, S. E., Meyer, C. K., Caldwell, C., \& Proctor, G. B. Jr. (2014). Trustworthiness, Justice, and the Mediating Lens. Journal of Business and Behavioral Sciences, 26(1), 55-74.

Clifton, J., \& Harter, J. (2019). It's the Manager: Gallup Finds the Quality of Managers and Team Leaders is the Single Biggest Factor in Your Organization's Long-term Success. Omaha, NE: Gallup Press.

Cohen-Carash, Y., \& Spector, P. (2001). The role of justice in organizations: a meta-analysis. Organizational Behavior and Human Decision Processes, 86(2), 278-321. https://doi.org/10.1006/obhd.2001.2958

Collins, J. (2001). Good to Great: Why Some Companies Make the Leap, And Others Don't. New York: Harper Collins.

Colquitt, J. A., Greenberg, J., \& Zapata-Phelan, C. P. (2005). What is organizational justice? A historical overview. Handbook of organizational justice. Lawrence Erlbaum Associates Publishers.

Colquitt, J. A., \& Rodell, J. B. (2011). Justice, Trust, and Trustworthiness: A Longitudinal Analysis Integrating Three Theoretical Perspectives. Academy of Management Journal, 54(6,) 1183-1206. https://doi.org/10.5465/amj.2007.0572

Colquitt, J. (2001). On the dimensionality of organizational justice: a construct validation of a measure. Journal of Applied Psychology, 86(3). https://doi.org/10.1037/0021-9010.86.3.386

Cooper, C. L., Liu, Y., \& Tarba, S. Y. (2014). Resilience, HRM practices and impact on organizational performance and employee well-being. International Journal of Human Resource Management 2015 Special Issue. https://doi.org/10.1080/09585192.2014.926688

Covey, S. R. (2013). The 7 Habits of Highly Effective People: Powerful Lessons in Personal Change. New York: Simon \& Schuster.

Covey, S. R. (2004). The 8th Habit: From Effectiveness to Greatness. New York: Free Press.

Cropanzano, R., Bowen, D. E., \& Gilliland, S. W. (2007). The Management of Organizational Justice. Academy of Management Perspectives, 21(4), 34-48. https://doi.org/10.5465/amp.2007.27895338

Deming, W. E. (2000). Out of the Crisis. Cambridge, MA: MIT Press.

DePree, M. (2004). Leadership is an Art. New York: Crown Publishing.

Derven, M. (2008). ONBOARDING. Academia.edu.

Ellinger, A. D., Ellinger, A. E., Bachrach, D. G., Wang, Y. L., \& Elmadağ Baş, A. B. (2011). Organizational investments in social capital, managerial coaching, and employee work-related performance. Management Learning, 42(1), 67-85. https://doi.org/10.1177/1350507610384329

Farr, J. L., \& Tippins, N. T. (Eds.). (2013). Handbook of employee selection. Routledge. https://doi.org/10.4324/9780203809808

Folger, R., \& Cropanzano, R. (1998). Organizational justice and human resource management. New York: Sage Publications.

Gatewood, R. D., Field, H. S., \& Barrick, M. R. (2015). Human Resource Selection. Boston, MA: Cengage Learning. 
Gomez-Mejia, L. R., Balkin, D. B., \& Cardy, R. L. (2015). Managing Human Resources. Boston, MA: Pearson Publishing.

Harrington, J. (2017). Survey: People's Trust Has Declined in Business, Media, Government, and NGOs. Harvard $\begin{array}{lllll}\text { Business } & \text { Review January, } & 16 & \end{array}$ https://hbr.org/2017/01/survey-peoples-trust-has-declined-in-business-media-government-and-ngos.

Hartley, D. E. (2004). Job Analysis at the Speed of Reality. 58(9), 20-22.

Hillman, J. (2010). Planning for Employee Onboarding: Finding Ways to Increase New Employee Success and Long-Term Retention. Noel-Levitz White Paper. Noel-Levitz, Inc.

Hosmer, L. T. (2010). The Ethics of Management. New York: McGraw

Hosmer, L. T. (1995). Trust: The Connecting Link between Organizational Theory and Philosophical Ethics. Academy of Management Review, 20(2), 379-403. https://doi.org/10.5465/amr.1995.9507312923

Kouzes, J. M., \& Posner, B. Z. (2011). Credibility: How Leaders Gain and Lose It, Why People Demand It. San Francisco, CA: Jossey-Bass. https://doi.org/10.1002/9781118983867

Mathis, R. L., Jackson, J. H., Valentine, S. R., \& Meglich, P. A. (2016). Human Resource Management. Boston, MA: Cengage Learning.

Mayer, R. C., Davis, J. H., \& Schoorman. (1995). An Integrative Model of Organizational Trust. Academy of Management Review, 20(3), 709-734. https://doi.org/10.5465/amr.1995.9508080335

McGregor, D. (2016). The Human Side of Enterprise, Annotated Edition. New York: McGraw-Hill Education.

McKenna, E. F., \& Beech, N. (2008). Human Resource Management: a concise analysis. Pearson Education.

Milkovich, G., Newman, J., \& Gerhart, B. (2013). Compensation. New York: McGraw-Hill.

Morgeson, F. P., Brannick, M. T., \& Levine, E. L. (2019). Job and work analysis: Methods, research, and applications for human resource management. Sage Publications.

Moriarty, J. (2020). What's in a Wage? A New Approach to the Justification of Pay. Business Ethics Quarterly, 30(1), 119-137. https://doi.org/10.1017/beq.2019.42

Noe, R. A. (1993). Employee training and development. Academia.edu.

Osibanjo, A. O., Adeniji, A. A., Falola, H. O., \& Heirsmac, P. T. (2014). Compensation packages: a strategic tool for employees' performance and retention. Leonardo Journal of Sciences, (25), 65-84.

Pfeffer, J. (1998). The Human Equation: Building Profits by Putting People First. Boston, MA; Harvard Business Review Press.

Phillips, J. J. (2012). Return on investment in training and performance improvement programs. New York: Routledge. https://doi.org/10.4324/9780080516257

Prien, E., Goldstein, L., Goodstein, J., \& Gamble, L. (2009). A practical guide to job analysis. New York: Pfeiffer.

Primeaux, P. S., Karri, R., \& Caldwell, C. (2003). Cultural insights to justice: A theoretical perspective through a subjective lens. Journal of Business Ethics, 46(2), 187-199. https://doi.org/10.1023/A:1025017024336

Rawls, J. (1999). A theory of justice. Oxford University Press.

Scarpello, V., \& Carraher, S. M. (2008). Are pay satisfaction and pay fairness the same construct? Baltic Journal of Management. https://doi.org/10.1108/17465260810844248

Schein, E. H., \& Schein, P. (2016). Organizational Culture and Leadership (5th ed.). San Francisco, CA: Jossey-Bass.

Shrouf, H., Al-Qudah, S., Khawaldeh, K., Obeidat, A., \& Rawashdeh, A. (2020). A study on relationship between human resources and strategic performance: The mediating role of productivity. Management Science Letters, 10(13), 3189-3196. https://doi.org/10.5267/j.msl.2020.5.002

Till, R. E., \& Karren, R. (2011). Organizational justice perceptions and pay level satisfaction. Journal of Managerial Psychology. https://doi.org/10.1108/02683941111099619

Van Buren III, H. J., Greenwood, M., \& Sheehan, C. (2011). Strategic human resource management and the decline of employee focus. Human Resource Management Review, 21(3), 209-219. https://doi.org/10.1016/j.hrmr.2011.02.004 


\section{Copyrights}

Copyright for this article is retained by the author(s), with first publication rights granted to the journal.

This is an open-access article distributed under the terms and conditions of the Creative Commons Attribution license (http://creativecommons.org/licenses/by/4.0/). 